\title{
Psychological and pedagogical aspects of ethnocultural identity formation in the Russian scientific discourse
}

\author{
I.A. Zakiryanova ${ }^{1 *}$, L.I. Redkina ${ }^{2}$, and L.V. Bura $^{3}$ \\ ${ }^{1}$ P.S. Nakhimov Black Sea Higher Naval School, Sevastopol, Russian \\ ${ }^{2}$ V.I. Vernadsky Crimean Federal University, Simferopol, Russia \\ ${ }^{3}$ V.I. Vernadsky Crimean Federal University, Simferopol, Russia
}

\begin{abstract}
In this article the problem of ethnocultural identity formation is considered in the context of the personal development problem, namely, as a person's awareness of oneself, one's environment as well as of oneself in one's relations with other people. Along with the genetically determined prerequisites, ethnocultural identity formation is influenced by sociocultural factors, a person's real life. The ethnocultural identity phenomenon is closely related to the methodological understanding of the foundations of deep, fundamental life meanings, values, and priorities. Ethnocultural identity and everything that relates to it - roots, historical destinies, ethnic culture, historical memory - are the most important values and life meanings of every person.
\end{abstract}

\section{A problem statement}

In the last two decades, pedagogical science has intensified its work on the methodological understanding of the basis of deep, fundamental life meanings, values, priorities, essentially related to the phenomenon of ethnocultural identity.

The need for the ethnocultural identity is caused by the need for each person to feel stability and security, in a certain order of one's own life which a person can find in the community of people of one's ethnic group. The problem of ethnocultural identity is also closely related to the issues of interethnic interaction which in the XXI century remain extremely relevant both in general for Russia, and in particular for the Crimea with its intensity of interethnic contacts. The maintenance of harmony and harmonization of social relations on the basis of preserved sociocultural and ethnocultural diversity with common systemic goals shared by every person, the formation of national pride sense with respect for other peoples should become the cornerstone of the entire education system.

\footnotetext{
*Corresponding author: prof-ped.gpa@mail.ru
} 


\subsection{The objective of the work}

In this regard, the study of students' ethnocultural identity formation is of particular importance and requires scientific justification. Therefore, the purpose of this article is to analyze the psychological and pedagogical aspects of ethnocultural identity formation in the Russian scientific discourse.

It should be noted that in the Russian scientific discourse until the early 90s of the last century, the concept of "ethnocultural identity" was not used practically giving way to the more traditional term "ethnic selfconsciousness". That is why the ethnocultural identity problem was considered until recently in the light of the concepts of "selfconsciousness of the individual", "ethnic selfconsciousness", and "national selfconsciousness". A lot of researches in Russian psychology are dedicated to the problem of ethnocultural identity viewed through the selfawareness prism. These studies can be divided into two large groups. The first group includes the works of L.S. Vygotsky, A.N. Leontiev, S.L. Rubinstein, B.G. Ananyev, A.V. Brushlinsky, A.G. Asmolov and other scientists in which the question of ethnocultural identity formation in the context of personal development problem is analyzed in general theoretical and methodological terms.

Another group is represented by studies which consider various aspects of ethnocultural identity, more specific issues related to the peculiarities of the structure, the mechanism of this phenomenon formation (I.I. Chesnokova, A.A. Bodalev, I.S. Kon, V.S. Mukhina, and other scientists).

\section{Results of the research}

The principles of mental development formulated in L.S. Vygotsky's cultural-historical theory of psyche and consciousness origin and formation, A.N. Leontiev and S.L. Rubinstein's psychological theory of activity, B.G. Ananyev's theoretical and experimental psychological teaching about human being, A.G. Asmolov's evolutionary-historical approach to personality, and others make it possible to consider the ethnocultural identity phenomenon in the context of a systematic approach as a person's awareness of oneself, one's environment, as well as oneself in one's relations with other people.

It is from the principle of a person's system organization position L.S. Vygotsky was the first scientist in the Russian psychology who considers the problem of selfconsciousness. Selfawareness in terms of ethnocultural identity is a person's awareness of one's experience as its transformation into a certain system that includes emotion, understanding and attitude to it. According to L.S. Vygotsky, it is reflection that allows a person to observe oneself from the side of one's own feelings, to internally differentiate the 'I' acting, reasoning and evaluating [1].

Of undoubted interest in connection with our problems are L.S. Vygotsky's reflections [2] on the need to consider the social environment as the main source of personal development. Personality is a social concept; it is something that is introduced into it by culture. A person is formed as a result of cultural development when a system of moral values of a person's personality is formed as a condition for him/her to acquire one's own identity (including ethnocultural one) which marks a significant system of social ties and relations for a person through which the picture of the world is perceived and realized. This is exactly the condition without which as well as without individual characteristics of a person the process of ethnocultural identity formation is impossible.

According to the Russian psychologists' researches, ethnocultural identity formation is ensured by the functioning of the interiorization mechanism through which the external interaction in the system of 'I and the other' passes "inside" a child, a teenager and thus determines one's individual psychological identity. In L.S. Vygotsky's opinion, “every 
higher form of behavior appears on the stage twice in its development - first as a collective form of behavior, as an interpsychic function, then as an intrapsychic function as a known mode of behavior" [3].

L.S. Vygotsky's idea about interiorization is continued and developed by A.N. Leontiev. He emphasizes that interiorization as a gradual transformation of external actions into internal, mental ones is a process that is forced to be realized in a person's ontogenetic development. A.N. Leontiev explains the need for it by the fact that the fundamental factor of the child's development is assimilation of the mankind's historical development achievements, including the achievements of human thought, human cognition [4]. Thus ethnocultural identity is the result of human appropriation of sociocultural development achievements, the experience of previous generations.

In the study of the mechanism of ethnocultural identity formation problem, one should not limit oneself to elucidating the biological prerequisites, but should proceed from the development of activities, their specific forms and types, as well as the connections and relations which they enter into with each other, since their development significantly changes the meaning of these prerequisites themselves [4]. In other words, a person has genetically determined prerequisites, but their influence on ethnocultural identity formation is mediated by sociocultural factors, and a person's real life. It is important that the values, needs, and beliefs that a person learns from the outside, in the process of social interaction, become one's own. According to A.N. Leontiev, ethnocultural identity is a holistic phenomenon that includes awareness not only of one's objective 'I' and its active beginning, but also of the universal 'I' contained in this specific, individual 'I' [4].

S.L. Rubinstein as well as A.N. Leontiev emphasizes the active position of the 'I' in the process of self-determination [5]. Mental processes are a person's special mental activity as a subject aimed at analyzing the picture of the world, at differentiating the significant and insignificant in a person's life, at synthesizing and generalizing the characteristics of objects in the surrounding world.

The mechanisms of interiorization and exteriorization which play an important role in ethnocultural identity formation are the subject of consideration in B.G. Ananyev's works. According to the scientist, ethnocultural identity formation is realized in the social environment; during this process, the structures of external social activity are transformed into structures of the internal plane of consciousness, then on the basis of the transformation of a number of internal structures formed on the basis of the interiorization of a person's external social activity, the process of generating external actions, etc. [6].

A.V. Brushlinsky [7] analyzing the problem of subject formation - in terms of ethnocultural identity - during mastering the culture, the entire cultural and historical experience of the mankind, believes that the formula of human mental development "from social to individual" and (more generally) "from external to internal" which is a basis of interiorization theory needs to be clarified according to which only one direction of development is recognized: only from the joint, interindividual, to the intra-individual. At the same time the sources of human activity are not taken into account, and all sociality is reduced to only one type of it - the (forced) influence of society on a person without taking into account all types of interaction (both individual and social) and especially a person's influence on society. And further, A.V. Brushlinsky quite rightly justifies his point of view considering that as a person grows up such phenomena as self-development, self-education, self-formation, aimed at the fullest possible realization of a person as a person, and accordingly a greater share belongs to internal conditions through which all external causes, influences, etc. always act.

The process of ethnocultural identity formation, according to A.V. Brushlinsky, involves a person's activity, independence as a subject who consciously makes one's choice and is responsible for it, on the one hand; and the process of a person's continuous 
interaction with the surrounding reality: the process of communication and one's activities - initially social, independent and creative - during which the development of universal values takes place, on the other hand. It is the universal values which are laid down in the foundation of ethnic culture since they, according to A.V. Brushlinsky, "form the most general and therefore especially strong foundation of spirituality on the basis of which everyone chooses and paves one's life path, forming more specific and private moral values and ideals" [7].

B.G. Ananyev as well as A.V. Brushlinsky believes that a person as a subject of communication and activity is formed not only in the process of education, but also in one's own life in society $[6,7]$.

Considering the question of a person's belonging to a certain ethnic community as a very significant personal characteristic, B.G. Ananyev believes that the loss of social unity, a sense of community and belonging leads to the breakdown of the personality's intraindividual component, to an identity crisis emergence and, as a result, to various manifestations of deviant behavior [6]. It should be noted that in this case, B.G. Ananyev's reasoning echoes the French sociologist and philosopher D.E. Durkheim's concept of anomie (lack of regulation) the main position of which is that a person without social support is disorganized, he/she experiences acute internal conflict, discord with oneself, loses the meaning of existence - all that disorganizes individual behavior [8].

According to A.G. Asmolov's concept, ethnocultural identity formation in the context of personal development should be considered as a systematic process in which three points are distinguished: individual (a term introduced by A.N. Leontiev) qualities as prerequisites for 'I' development, socio-historical lifestyle as a source of 'I' development and joint activity as the basis for the implementation of life activity in the system of social relations. Moreover, the individual prerequisites and the socio-historical way of life as a source of ' $\mathrm{I}$ ' development are not parallel lines of biogenetic and sociogenetic programs of human life in society. In A.G. Asmolov's opinion, “from the very moment of human movement in society these prerequisites begin to actively participate in the life of a particular evolving system, influence its development, transform from prerequisites as a result of its development, and be used by the individual as a means of achieving its goals" [9].

The analysis of studies of ethnocultural identity problem in Russian psychology shows that the most interesting questions for scientists are those related to the mechanism of ethnocultural identity formation, its structure and level organization. Thus I.I. Chesnokova defining the structure of ethnocultural identity reveals its three components: selfknowledge, emotional and value attitude to oneself and self-regulation of individual behavior. Ethnocultural identity formation is presented as a process of self-regulation by a person of one's actions in the sphere of behavior and activity on the basis of self-knowledge and emotional-value attitude to oneself.

I.I. Chesnokova [10] distinguishes two levels in the process of ethnocultural identity formation according to the criterion of the framework in which a person's knowledge about oneself is correlated. At the first level this correlation occurs within the framework of ' $\mathrm{I}$ ' and 'another person' comparison. First, a certain quality is perceived and understood in another person, and then transferred to oneself. The corresponding internal techniques at this level are mainly self-perception and self-observation. At the second level, the correlation of self-knowledge occurs mainly in the process of auto-communication that is within the framework of 'I and I'. A person operates with ready-made knowledge about oneself, to some extent already formed, acquired at different times and in different situations. At this level, a person correlates one's behavior with the motivation that one implements. In addition, the motives themselves are evaluated from the point of view of social and internal requirements. Ethnocultural identity formation in general means a 
person's sense of self-worth formation, one's social value as the ethnic community representative.

I.I. Chesnokova comes to the conclusion about the integrative nature of the psychological mechanism of ethnocultural identity formation and preservation. This integrativity is expressed in the fact that the process of ethnocultural identity formation involves not only individual mental processes in various combinations, but also the personality as a whole - systems of one's mental properties, values, features of motivation, acquired experience at different generalization levels, as well as person's emotional state at the moment [11]. According to I.I. Chesnokova, ethnocultural identity is a necessary condition for the integrity and continuity of individual's inner world formation and functioning.

A.A. Bodalev [13] studying social perception draws attention to the relationship between the processes of another person's self-knowledge and cognition.

A synthesis of philosophical, socio-psychological, general psychological, cultural and historical aspects, theoretical issues and analysis of experimental data is traced in I.S. Cohn's works. This undoubtedly makes it possible to explore the ethnocultural identity problem more comprehensively and deeply.

I.S. Kohn's reflections on the dynamics of constancy and variability of ethnocultural identity in the light of the problem of personality and one's properties are of particular interest [13]. On the one hand, ethnocultural identity presupposes genotypic constancy that is the presence of certain unchanging, deep, biologically stable qualities that may or may not manifest themselves in different ways at different stages of life, but persistently determine a person's mental reactions and behavior throughout one's life. On the other hand, culturally determined human traits, on the contrary, are more variable and depend on sociocultural conditions. At the same time it is impossible not to take into account the fact that a person is always a more or less active subject, or at least a participant in one's own personal formation.

As V.S. Mukhina approves, ethnocultural identity formation involves two stages. The first stage is the acquisition of identity through the mechanism of interpersonal identification (awareness of the name, claim to recognition, temporary awareness, sexual identification, awareness of rights and obligations). The second stage is a worldview and a personal meanings system formation. At this stage the mechanisms of identification and isolation operate on a cognitive and emotional level. Identification is considered as a mechanism of comprehensive human essence appropriation by one individual; isolation is considered as a mechanism of the individual's defense of one's natural and human essence [14]. Identification and isolation, as V.S. Mukhina believes, are two equally significant and at the same time dialectically opposite components of a single mechanism that contributes to ethnocultural identity formation as an individual and personal phenomenon.

In addition to the reality of nature itself, V.S. Mukhina considers the reality of culture to be a condition for ethnocultural identity formation. She offers the following classification of human existence realities determined by cultural development and historically determined:

1. The reality of the object world that is the objects of nature and man-made objects that were created by humanity in the process of historical development, as well as the system of human relations to these objects. These relationships are embodied in the language, folk traditions, customs, and rituals.

2. The reality of figurative-sign systems that is systems of signs that affect the internal mental activity determining it, and determine the real world new objects creation at the same time. Sign systems are divided into linguistic systems (language as a means of cultural development, first; as a source of deep attitudes to the value attitude to the surrounding world formation: people, nature, the object world, the language itself, 
secondly; as concentration of collective representations, identifications, and alienations of human ancestors and contemporaries, thirdly) and non-linguistic (signs-signs, signs-copies, autonomous signs, signs-symbols, signs-standards, non-linguistic signs).

3. Natural reality that is the source and condition of human life. Nature enters into the reality of the objective world and into the reality of the figurative and symbolic systems of culture.

4. The reality of social space that is the material and spiritual side of human existence along with communication, human activities and the system of rights and obligations [14].

V.S. Mukhina's research shows how in the process of a person's mental development the system of stable relations in the sphere of value orientations that has developed in the history of mankind which allows a person to perceive oneself as both a part of one's own social community and a unique person assigned by a person. In our opinion, this corresponds to ethnocultural identity semantic field.

Thus this article attempts to analyze the psychological research of the Russian scientists in realizing the system of students' ethnocultural identity formation in the context of personal development problem, namely: as a person's awareness of oneself, one's environment as well as oneself in one's relationships with other people. Along with the genetically determined prerequisites, ethnocultural identity formation is influenced by sociocultural factors, a person's real life.

Such an analysis which is based on the scientific potential proven by historical practice, on the one hand, contributes not only to the objective assessment of the process of ethnocultural identity formation, but also to the understanding of the ethnocultural identity phenomenon in the context of personal development. On the other hand, it allows us to identify possible ways to form ethnocultural identity, as well as to design the most effective methods and forms of the educational process in the higher education system that contribute to students' ethnocultural identity formation. We are talking about the use in the educational process of methods and techniques focused on social value relations; on selfknowledge, self-analysis, self-control and self-regulation; on joint activities - in a word, the use of methods and techniques allowing to actualize such areas of young people's mental life as cognitive, affective and behavioral ones, the activation of which is fundamental for ethnocultural identity formation.

\section{Conclusions}

The analysis of the psychological and pedagogical aspects of ethnocultural identity formation in the Russian scientific discourse allows us to draw the following conclusions.

Ethnocultural identity is the result of a person's appropriation of the sociocultural development achievements, previous generations' experience that is a person's awareness of one's objective relations with the world. Being conscious, these connections are interwoven into the personality's concept, into a person's general system of value orientations and life meanings.

A person's belonging to a certain ethnic community is an essential personal characteristic. The loss of social unity, a sense of community and belonging leads to the breakdown of a personality's intraindividual component, the emergence of an identity crisis and, as a result, various manifestations of deviant behavior.

Ethnocultural identity formation is a complex, time-bound process of mediated selfknowledge: from single situational images, through the integration of such numerous images into a holistic education - into the Self-concept as a subject who is different from other subjects.

The mechanisms of interiorization and exteriorization play an important role in the process of ethnocultural identity formation. 
Ethnocultural identity formation is possible only when a person is included in the general system of relationships of people in society which are expressed through the concept of activity, its meaning-forming motives. In the process of a person's continuous interaction with the surrounding reality: in the process of communication and one's activities - initially social, independent and creative - the development of universal values which are laid down in the foundation of ethnic culture takes place.

The process of ethnocultural identity formation involves the activity, independence of a person as a subject of one's own life activity who consciously makes one's choice and is responsible for it.

The use in the educational process of interactive methods and techniques focused on social value relations; on self-knowledge, self-analysis, self-control and self-regulation; on joint activities allow to actualize such areas of young people's mental life as cognitive, affective and behavioral ones the activation of which is fundamental for students' ethnocultural identity formation.

\section{References}

1. L.S. Vygotsky, Collected works in 6 volumes: Vol. 2. Problems of general Psychology, 504 (Moscow: Pedagogy, 1982)

2. L.S. Vygotsky, Collected works in 6 volumes: Vol. 4. Child psychology, 432 (Moscow: Pedagogika, 1984)

3. L.S. Vygotsky, Psychology of development as a cultural phenomenon: Selected psychological works, 512 (Moscow, 1996)

4. A.N. Leontiev, Activity. Consciousness. Personality, 352 (Moscow: Smysl, Akademiya, 2005)

5. S.L. Rubinstein, Fundamentals of general psychology, 720 (St. Petersburg: Peter, 2002)

6. B.G. Ananyev, Human being as a subject of knowledge, 288 (St. Petersburg: Peter, 2001)

7. A.V. Brushlinsky, The problem of the subject in psychological science, Psychological Journal, 6, 6-10 (1991)

8. E. Durkheim, Suicide: Sociological etude, 399 (Moscow: Mys1, 1994)

9. A.G. Asmolov, Personality psychology: Cultural and historical understanding of human development, 528 (Moscow: Sense: Publishing Center "Academy", 2007)

10. I.I. Chesnokova, Problem of self-awareness in psychology, 144 (Moscow: Nauka, 1977)

11. I.I. Chesnokova, Problem of self-awareness in psychology, 260 (Moscow: Pragma, 1997)

12. A.A. Bodalev, Perception and understanding of a person by a person, 200 (Moscow Publishing House, 1982)

13. I.S. Kohn, Constancy and variability of personality, Psychological Journal, 4, 126-136 (1987)

14. V.S. Mukhina, Problems of the genesis of personality, 103 (Moscow: MSPI, 1985) 